\title{
PAPERS
}

\section{Incidence of advanced chronic renal failure and the need for end stage renal replacement treatment}

\author{
T G Feest, C D Mistry, D S Grimes, N P Mallick
}

TABLE I - Number of patients (per million population) accepted for dialysis each year in European countries

\begin{tabular}{lcc}
\hline & 1982 & 1988 \\
\hline Austria & $38 \cdot 1$ & $95 \cdot 7$ \\
Belgium & $39 \cdot 6$ & $85 \cdot 2$ \\
Israel & $58 \cdot 2$ & $80 \cdot 0$ \\
Federal Republic of & & \\
$\quad$ Germany & $44 \cdot 0$ & $77 \cdot 0$ \\
Holland & $27 \cdot 4$ & $65 \cdot 3$ \\
Sweden & $41 \cdot 3$ & $64 \cdot 3$ \\
Switzerland & $44 \cdot 5$ & $61 \cdot 8$ \\
Greece & $18 \cdot 8$ & $59 \cdot 2$ \\
Spain & $32 \cdot 7$ & $57 \cdot 1$ \\
France & $30 \cdot 9$ & $56 \cdot 3$ \\
United Kingdom & $19 \cdot 9$ & $55 \cdot 1$ \\
Italy & $33 \cdot 8$ & $54 \cdot 7$ \\
Norway & $37 \cdot 3$ & $52 \cdot 7$ \\
Denmark & $26 \cdot 9$ & $52 \cdot 5$ \\
Ireland & $19 \cdot 4$ & $33 \cdot 8$ \\
& & \\
\end{tabular}

Renal Unit, Royal Devon and Exeter Hospital (Wonford), Exeter EX2 5DW

T G Feest, MD, consultant nephrologist

Manchester Royal Infirmary, Manchester M13 9WL

C D Mistry, MD, lecturer in medicine

N P Mallick, FRCP, consultant nephrologist

Blackburn Royal Infirmary, Blackburn BB2 3LR

D S Grimes, FRCP, consultant physician

Correspondence to: Dr Feest.

$\operatorname{BrMed} \mathcal{f} 1990 ; 301: 897-900$

\section{Abstract}

Objective-Todetermine the age related incidence of advanced chronic renal failure in two areas of England.

Design-Prospective study of patients newly identified as having advanced chronic renal failure within a two year period; subsequent monitoring of patients' clinical course for a further 26 months.

Setting-Devon and Blackburn.

Subjects-Those patients in a population of 708997 who developed advanced chronic renal failure (serum creatinine concentration $>500 \mu \mathrm{mol} / \mathrm{l}$ ) for the first time during a two year period.

Main outcome measures and results -210 Patients (148 per million population per year) developed advanced chronic renal failure, $117(51 \%)$ of whom were over 70 . The age related incidence rose from 58 per million per year in those aged $20-49$ to 588 per million per year in those aged 80 or over. Only $54 \%$ (113) of patients were referred to a nephrologist; 120 patients $(57 \%)$ needed dialysis or died within three months of presenting without receiving dialysis, and $187(89 \%)$ died or needed dialysis within three years. After those unsuitable for further treatment had been excluded, 78 patients per million population per year aged under 80 needed to start long term renal replacement treatment.

Conclusions-Many patients suitable for renal replacement treatment are still not referred for nephrological opinion and are denied treatment. If the treatment rate in the United Kingdom rose from the 1988 rate of $55 \cdot 1$ per million per year to 78 per million per year then the number of patients receiving treatment would rise to about 800 per million. This is double the present number and has considerable but predictable resource implications for the NHS.

\section{Introduction}

The number of patients with advanced chronic renal failure accepted for long term renal replacement treatment in the United Kingdom has lagged behind that in most other countries in western Europe. In 1982 the United Kingdom treated 19.9 new patients per million population for end stage renal failure, compared with 44.0 in the Federal Republic of Germany and 41.3 in Sweden (table I).' The number of patients under 60 accepted for treatment was similar to that in other European countries, but there were fewer diabetic patients and patients over $60-12 \%$ of British patients compared with $31 \%$ in Germany and $34 \%$ in Sweden, for example. Nephrologists knew that these older and diabetic patients were being turned away because of lack of resources. As a result of this low acceptance rate the government in 1984 set a target of at least 40 patients per million to start treatment each year.

By 1986, when this study started, the number of patients accepted for treatment of end stage renal failure in the United Kingdom had risen to $43 \cdot 1$ per million, still behind most other western European countries (Federal Republic of Germany 59.4, Sweden $62 \cdot 1) .^{2}$ Unless the incidence of advanced chronic renal failure in the United Kingdom was lower than in other European countries, patients suitable for treatment were being turned away. Nephrologists were turning away fewer people but suspected that many patients they would accept for treatment were not being referred for consideration.

To assess the needs for dialysis and transplantation and to plan the future treatment of end stage renal failure in the United Kingdom the incidence of advanced chronic renal failure must first be known. Some estimates have already been made. From figures in the Registrar General's statistical review of 1962 de Wardener suggested that 140 patients per million per year developed advanced chronic renal failure, 45 of whom were in the age range $16-55 .^{3}$ In 1972 in a Scottish survey Pendreigh et al found that the death rate from renal failure under the age of 65 was 96 per million. ${ }^{+}$By circulating a questionnaire to general practitioners McGeown assessed in 1972 that the incidence of advanced chronic renal failure in those under 60 was 38 per million per year. ${ }^{5}$ Surveys using death certificates are unreliable, however, and the other surveys did not assess the incidence of end stage renal failure in all age groups, nor was it possible then to study the patients prospectively to determine the need for long term renal replacement treatment in the whole population.

In the present report, undertaken as part of the Renal Association's study of the provision of services for chronic renal failure, we have estimated the incidence of advanced chronic renal failure using the principle that for renal failure to be diagnosed a blood test must be done. Some patients may die of renal failure without the diagnosis ever being considered; thus our estimate of the incidence of advanced chronic renal failure is a conservative one. We defined advanced chronic renal failure as occurring when a serum creatinine concentration $>500 \mu \mathrm{mol} / \mathrm{l}$ was first recorded and then remained above this level. Not all of these patients would need dialysis; the number needing dialysis was assessed by following up and analysing the cohort.

\section{Methods}

The study covered three health districts, each with a stable population and a negligible cross boundary flow of patients. Each district has only one biochemical pathology laboratory. The 1988 census gave populations of 308647 for Exeter Health District; 135550 for North Devon district; and 264800 for Blackburn, Hyndburn, and Ribble Valley district. North Devon is a rural area, Blackburn is urban, and Exeter is mixed. Exeter has a renal unit to which North 
Devon referred most patients; Blackburn, Hyndburn, and Ribble Valley had no renal unit at the time of the survey and referred to Manchester or, latterly, Preston.

In each of these geographical areas the single pathology laboratory always measured serum creatinine concentration whenever electrolyte concentrations were requested. Over the two years starting 1 January 1986 all creatinine results were screened and any patient with a concentration $>500 \mu \mathrm{mol} / \mathrm{l}$ was identified. The notes were studied subsequently or in cases of blood tests initiated by the general practitioner he or she was contacted to obtain further information. The last follow up assessment was made on 1 March 1990 for those referred to a renal unit. For those not referred follow up was completed by May 1989 .

Patients living within the defined geographical areas were included from the first time the serum creatinine concentration rose above $500 \mu \mathrm{mol} / \mathrm{l}$, provided that it remained over 500 , or if necropsy or subsequent history confirmed the diagnosis of advanced chronic renal failure. The case histories of those patients who died without dialysis or who were not referred to a renal unit were assessed independently by all four authors to see whether dialysis or transplantation might have been suitable.

The confidence intervals of the sampling errors were assessed by calculating the standard error of the proportions.

\section{Results}

When any of the results were calculated separately for each district there was no significant difference between the districts except for the referral patterns.

\section{INCIDENCE OF ADVANCED CHRONIC RENAL FAILURE}

There were 451 patients (295 Devon, 156 Blackburn) with serum creatinine concentrations $>500 \mu \mathrm{mol} / \mathrm{l}$, of whom five could not be traced either because wrong names were recorded on the pathology forms or because they were transient holiday visitors. In all, 193 (125 Devon, 68 Blackburn) had acute renal failure and

TABLE II - Age related incidence of advanced chronic renal failure

\begin{tabular}{rccc}
\hline Age range (years) & \% Of population ${ }^{\star}$ & $\begin{array}{c}\text { No }(\%) \text { of patients in 2 years } \\
(\mathbf{n}=210)\end{array}$ & $\begin{array}{c}\text { Age related incidence (per million per year) } \\
(\mathbf{9 5 \%} \text { confidence interval) }\end{array}$ \\
\hline $0-20$ & 25 & $2(1)$ & $6(-2$ to 14$)$ \\
$20-49$ & 39 & $32(15)$ & $58(38$ to 78$)$ \\
$50-59$ & 11 & $25(12)$ & $160(96$ to 224$)$ \\
$60-69$ & 11 & $44(21)$ & $282(197$ to 367$)$ \\
$70-79$ & 8 & $57(27)$ & $503(370$ to 636$)$ \\
$\geqslant 80$ & 6 & $50(24)$ & $588(422$ to 754$)$
\end{tabular}

$\star^{\star}$ Office of Population Censuses and Surveys (1988); total population (Blackburn, Exeter, North Devon) 708997.

TABLE III - Survival time to dialysis or death without dialysis of patients in Devon

\begin{tabular}{|c|c|c|c|c|c|c|c|}
\hline & \multicolumn{7}{|c|}{ Time (months) } \\
\hline & $<1$ & $1-$ & $3-$ & $12-$ & 24- & $36-48$ & Total \\
\hline \multicolumn{8}{|c|}{ Patients referred to nephrologist } \\
\hline No surviving to dialysis & 16 & 9 & 10 & 5 & 6 & 2 & 48 \\
\hline No dying & 9 & 6 & 6 & 2 & & & 23 \\
\hline No still alive without dialysis & & & & & 1 & 4 & 5 \\
\hline Total & 25 & 15 & 16 & 7 & 7 & 6 & 76 \\
\hline \multicolumn{8}{|c|}{ Patients not referred to nephrologist } \\
\hline No dying & 29 & 5 & 10 & 2 & & & 46 \\
\hline No still alive without dialysis & & & & & 2 & 5 & 7 \\
\hline All patients & 54 & 20 & 26 & 9 & 9 & 11 & 129 \\
\hline
\end{tabular}

253 (165 Devon, 88 Blackburn) had non-acute renal failure. Of those with non-acute renal failure, 43 (36 Devon, 7 Blackburn) had end stage renal failure as a concurrent event in the terminal phase of longstanding myeloma or malignant disease of the prostate, bladder, cervix, or ovary. These were defined as having "terminal" renal failure and were excluded from further analysis because they died of their primary disease.

Only those 210 patients with advanced chronic renal failure are considered further in this paper (129 Devon, 81 Blackburn). This is a rate of $148(95 \%$ confidence interval 128 to 168 ) per million per year (145 (118 to 172) Devon, 153 (119 to 187) Blackburn).

Only $113(54 \%)$ of the patients were referred to a nephrologist. The incidence of advanced chronic renal failure rose steeply in patients aged over 49 , and half the patients were 70 or over (table II). This is even more striking when the incidence per million population at risk in each age group is calculated: the incidence rose from 60 per million per year among those aged 20-49 to 282 per million per year among those in their $60 \mathrm{~s}$ and 588 among those in their $80 \mathrm{~s}$ (table II).

Blackburn has a sizable Asian community. Asians comprised $8 \%$ of those with renal failure (10 patients); but this is not thought to represent a significantly different incidence of chronic renal failure in the Asian population.

\section{SUBSEQUENT PROGRESS OF PATIENTS}

The progress of the patients is charted in the figure. Of those referred to the renal unit, $74(65 \% ; 52$ per million per year) were given dialysis (Devon 53 per million per year, Blackburn 49 per million per year). Thirty two referred patients died without dialysis (Devon 23 (30\%), Blackburn $9(24 \%))$. Seven patients were still alive without dialysis, of whom three were expected to start dialysis within one year.

Survival to dialysis or death without dialysis was charted in the Devon cohort (table III): $42 \%$ (54 patients) survived less than one month, $57 \%$ (74) less than three months, and $89 \%$ (118) less than three years. Of those referred to the renal unit, $21 \%$ (16 patients) received dialysis within one month, 33\% (25) within three months, and $61 \%(46)$ within three years. Of the referred patients, $30 \%$ (23) died without dialysis, nine of these within the first month. Over half of the nonreferred patients (29/53) died within one month. Only nine patients not receiving dialysis remained alive 27 months after the survey finished; three others were lost to follow up.

Age seems to be a major determinant of referral to the renal unit (table IV). Only two patients under the age of 60 were not referred, but the proportion rose with age such that no patients over 90 were referred. Of patients aged between 60 and 80 , an age range that nephrologists consider suitable for treatment, $52(51 \%)$ were not referred; the districts without a renal unit referred a significantly smaller proportion $(27 \%$ and $39 \%$ ) than the district with a renal unit $(67 \%)$ (standard error of percentage differences: Exeter $v$ North Devon $13.56, \mathrm{p}<0.01$; Exeter $v$ Blackburn 10.33, $\mathrm{p}<0.01$; Exeter $v$ both $9 \cdot 58, \mathrm{p}<0.03)$.

There seemed to be a difference in referral pattern between the sexes: $58 \%$ of patients (122) were men, $63 \%$ of whom (77) were referred to the renal unit as

TABLE IV-Referral to renal unit by age and district

\begin{tabular}{|c|c|c|c|c|c|c|c|c|c|}
\hline & \multicolumn{3}{|c|}{ Patients $<60$} & \multicolumn{3}{|c|}{ Patients 60-79 } & \multicolumn{3}{|c|}{ Patients $\geqslant 80$} \\
\hline & Exeter & North Devon & Blackburn & Exeter & North Devon & Blackburn & Exeter & North Devon & Blackburn \\
\hline $\begin{array}{l}\text { No }(\%) \text { referred } \\
\text { No not referred }\end{array}$ & $\begin{array}{c}30(97) \\
1\end{array}$ & $7(100)$ & $20(95)$ & $\begin{array}{l}28(67) \\
14\end{array}$ & $4_{11}^{4(27)}$ & $\begin{array}{l}17(39) \\
27\end{array}$ & $\begin{array}{l}7(29) \\
17\end{array}$ & 10 & 16 \\
\hline
\end{tabular}


compared with $51 \%$ (45) of the women. Many more of those patients aged 80 or over were women, however, and the apparent difference between the sexes simply reflects the lower referral rate of older patients.

In Devon 23 of the patients referred to the renal unit died without receiving dialysis. The five aged 80 or over all died within one month of referral. Of the eight in their 70s who died, three died of advanced chronic renal failure: on review we considered these patients suitable for treatment. Only three under 70 died of advanced chronic renal failure: one refused treatment; one diabetic patient in his $40 \mathrm{~s}$ had advanced dementia, widespread gangrene, and postural hypotension and was blind - both he and his family agreed that further active intervention would be inappropriate; and one patient in his 50s was considered untreatable owing to advanced widespread arterial disease, which necropsy showed was due to polyarteritis nodosa - he may have been treatable. Four of the 18 patients aged under 80 should probably have been offered dialysis.

Of the 97 patients not referred for a specialist nephrological opinion, 54 were under 80 . When last traced (18 months after the survey ended) 15 were still alive. In 68 cases non-referral seemed appropriate in view of concomitant conditions such as advanced cardiovascular disease, severe stroke, dementia, or

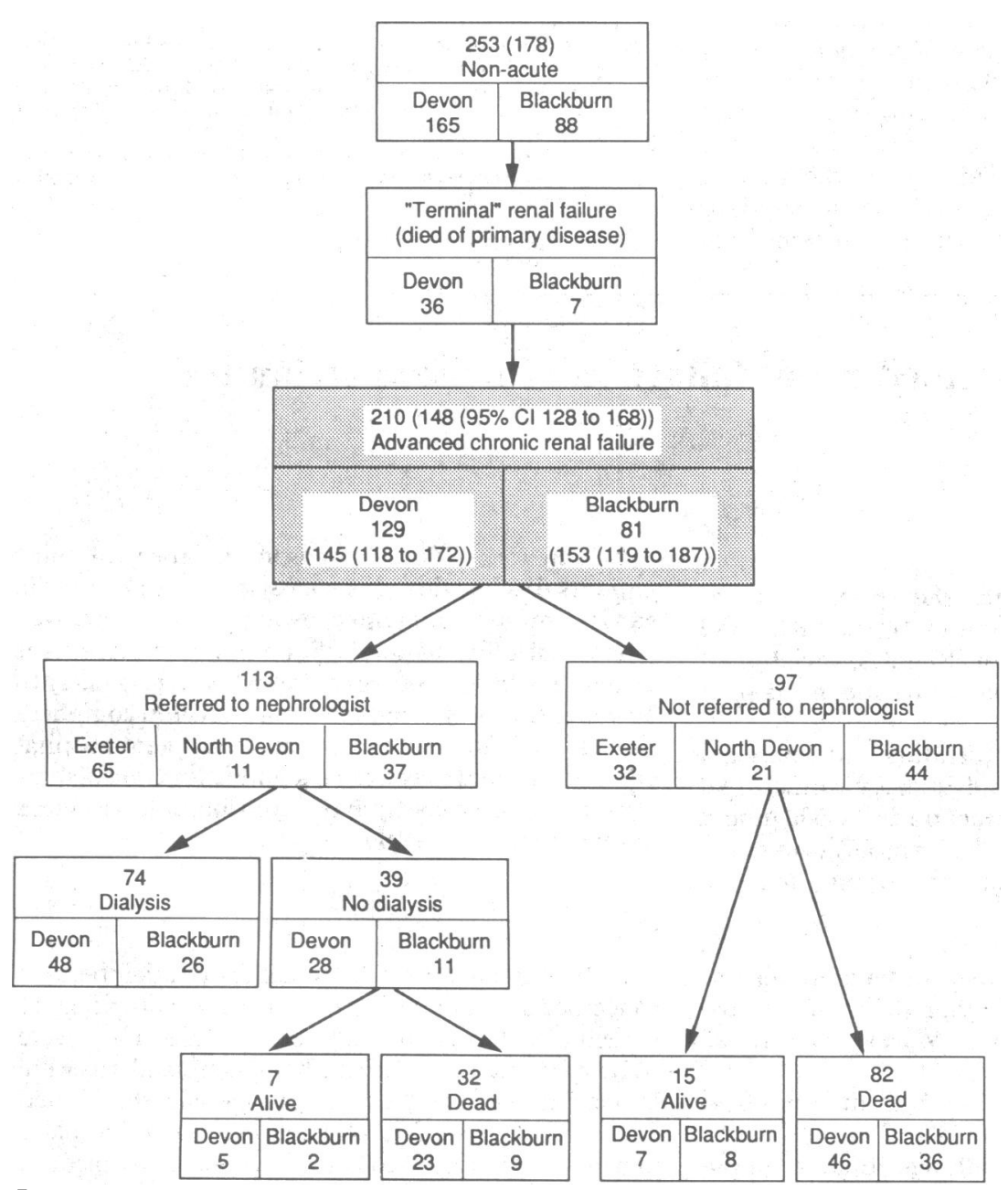

Progress of patients (number per million per year) with renal failure

TABLE V-Estimated need for dialysis among patients in Devon and Blackburn. Numbers in parentheses are per million population per year

\begin{tabular}{lcccc}
\hline & No receiving dialysis & Dialysis imminent & $\begin{array}{c}\text { Inappropriate referral, } \\
\text { non-referral, and errors }\end{array}$ & Total need for dialysis \\
\hline $\begin{array}{l}\text { Devon } \\
\text { Blackburn }\end{array}$ & $48(54)$ & 3 & $\begin{array}{l}19(21) \\
14(26)\end{array}$ & $\begin{array}{c}70(79) \\
40(76)\end{array}$ \\
\hline Total & $74(49)$ & 3 & $33(23)$ & $\begin{array}{c}110(78 ; 95 \% \text { confidence } \\
\text { interval 63 to 93) }\end{array}$ \\
\hline
\end{tabular}

multiple problems in immobile elderly people, or stable renal function after relief of obstructive uropathy. We estimate, however, that 29 patients under the age of 80 could have received dialysis and should have been referred for a nephrologist's opinion; only four of these were alive at the end of follow up. Most of the deaths were attributable to renal failure.

In Devon $10(8 \%)$ of the patients (11 per million per year) were diabetic; in Blackburn $10(12 \%)$ were diabetic (19 per million per year). Nine of the diabetic patients in Devon were referred for a nephrologist's opinion; six were insulin dependent. In Exeter health district (from which nine of the 10 diabetic patients in Devon with renal failure originated) there are over 3000 patients with diabetes, of whom over 600 are insulin dependent. Four of the diabetic patients have received dialysis, one has moved away, one was aged over 80 , three died from non-renal causes, and one (already discussed) was not offered dialysis. In Blackburn only five of the 10 patients were referred for a nephrologist's opinion (this referral rate has risen since the study was completed). The incidence of diabetic patients with a creatinine concentration $>500 \mu \mathrm{mol} / \mathrm{l}$ is similar to that estimated in the joint report of the British Diabetic Association, the Renal Association, and the Royal College of Physicians, ${ }^{6}$ which highlighted an apparent shortfall between those with a creatinine concentration $>500 \mu \mathrm{mol} / \mathrm{l}$ and those receiving dialysis. Our figures suggest that in some areas this may be due in part to patients dying of nonrenal causes after the serum creatinine concentration has risen above $500 \mu \mathrm{mol} / \mathrm{l}$ but before dialysis is needed, rather than to discrimination against diabetic patients.

\section{Discussion}

The results from Blackburn and Devon, two areas with different socioeconomic characteristics, were remarkably similar (figure). Even though a greater number of cases in Exeter were judged to be "terminal" (this may have been a matter of definition), the incidence of non-acute renal failure was almost identical in the two areas. This encourages us to believe that these results may be representative of the United Kingdom as a whole.

The follow up showed that patients with a serum creatinine concentration $>500 \mu \mathrm{mol} / \mathrm{l}$ rapidly reach end stage renal failure or death (over half in three months). Only $6 \%$ of those referred to the renal units who did not receive dialysis were alive after 23 months of follow up. Over half of those who received dialysis did so within three months of the first creatinine concentration $>500 \mu \mathrm{mol} / \mathrm{l}$, an inadequate time for proper preparation for such treatment. This emphasises the need for early referral for a nephrologist's opinion whenever possible.

Fewer patients were referred from Blackburn and North Devon health districts - that is, districts without a renal unit-than from Exeter. This indicates that some decentralisation of renal care facilities would probably lead to a geographically more even referral and treatment pattern.

As the incidence of renal failure rises steeply with age the need for dialysis may vary according to the age distribution of populations of different health districts. The effects of such variations can be predicted from table II. The implications of treating the over 60 s are considerable. In these three districts for every million total population 41 people aged under 60 developed advanced renal failure each year, as did 72 under 70 and 112 under 80 .

From these figures the need for dialysis can be estimated (table V). Of the cohort of patients identified, 74 (52 per million per year) have already received 
dialysis, and within one year another three will probably have done so. Adding those under 80 who died but who we consider should have been referred for treatment, those alive in imminent need of referral, and errors of judgment by staff of the renal unit, we reach a figure of 78 (63 to 93) patients per million per year needing to start dialysis.

Occasional errors will continue to be made, and some people will always refuse treatment or be lost to follow up. On the other hand, our estimate does not include patients aged 80 or over. Many such people are remarkably fit and in the past year we have started several on dialysis. On balance, therefore, about 80 patients per million per year seems a reasonable figure for patients needing dialysis in these two populations. The latest figures from the European Renal Association show that $55 \cdot 1$ patients per million per year started treatment for end stage renal failure in the United Kingdom in 1988.

Since the end of the study the referral rates from both North Devon and Blackburn have risen. In 1989 in both Exeter and North Devon health districts over 70 patients per million started end stage renal failure treatment.

These figures suggest that despite the increase in provision of treatment for end stage renal failure in the United Kingdom during the past decade treatment is still not offered to all who could benefit from it. A figure of 80 patients per million population per year needing dialysis is comparable with that for patients starting dialysis in many western European countries. Health districts should be budgeting for this acceptance rate of new patients and planning for the steadily increasing numbers of patients surviving on dialysis or receiving kidney transplants. With the current death rate of around a tenth of patients a year the stock of patients receiving end stage renal failure treatment could grow to nearly 800 per million population. Health districts can draw some comfort from the fact that the need for dialysis and transplantation is not unlimited; indeed, some health districts have already reached an acceptance rate of 70 per million per year and are starting to meet the real need.

This work was initiated by a subcommittee of the Renal Association set up to study the provision of renal services in the United Kingdom. The study was supported by grants from the Medical Research Council. We thank Elizabeth Boylan in Exeter and Sheila Maskery in Blackburn, who painstakingly collected the initial data, and Dr Ian Lewin who helped to collect and analyse the data from North Devon. We also thank the physicians of the three health districts who agreed to their patients being assessed in this way and the pathology laboratories for their cooperation.

1 Wing AJ, Broyer M, Brunner FP, et al. Combined report on regular dialysis and transplantation in Europe, XIII, 1982. Proceedings of the European Dialysis and Transplant Association 1983;20:5-78.

2 European Dialysis and Transplant Association Registry. EDTA registry centre survey, 1985. Nephrol Dial Transplant 1987;2:475-87.

3 De Wardener HE. Ethical and economic problems associated with intermitten heamodialysis. In: Wolstenholme GEW, O'Connor M, eds. Ethics in medical progress. London: Churchill, 1966.

4 Pendreigh DM, Howitt LF, MacDougall AI, et al. Survey of chronic renal failure in Scotland. Lancet $1972 ; \mathrm{i}: 304-7$.

5 McGeown MG. Chronic renal failure in Northern Ireland 1968-1970. Lancet $1972 ; \mathrm{i}: 307-10$.

6 Joint Working Party on Diabetic Renal Failure of the British Diabetic Association, Renal Association, and the Research Unit of and Royal College etic renal failure in patients identified in the 1985 United Kingdom survey. Br Med $f$

Tufveson G, Geerlings W, Brunner FP, et al. Combined report on regular dialysis and transplantation in Europe, XIX, 1988. Nephrol Dial Transplan 1989;4(suppl 2):5-32.

(Accepted 17 fuly 1990

\title{
Prevalence of advanced renal failure in Northern Ireland
}

\author{
Mary G McGeown
}

Abstract

Objective-To determine the prevalence of advanced chronic renal failure in Northern Ireland as part of an assessment by the Renal Association of the level of service provision for treatment of such patients.

Design-Prospective notification of patients reaching a defined level of advanced chronic renal failure (serum creatinine concentration $\geqslant 500 \mu \mathrm{mol} / \mathrm{l}$ or blood urea concentration $\geqslant 25 \mathrm{mmol} / \mathrm{l}$ ) within one year and follow up for at least three, and, at most, four years after notification.

Setting-Northern Ireland.

Patients - 122 Patients with a serum creatinine or blood urea concentration higher than the defined level newly detected from 1 March 1985 to 28 February 1986. tion.

Main outcome measure-Survival after notifica-

Queen's University of Belfast, Belfast Mary G McGeown, MD, professorial fellow

Correspondence to: Professor McGeown, Department of Medicine, University Floor, Tower, Belfast City Hospital, Belfast BT9 7AB.
Results-77 Patients of all ages/million population/year had advanced chronic renal failure compared with $67 / \mathrm{million} /$ year between the ages of 5 and 80 found in an earlier study of the same population. $62 \%$ Of the patients were older than 50 years. Seventeen $(14 \%)$ of the patients either required dialysis or died within one month of notification, $51(42 \%)$ survived for at least three months, and $23(19 \%)$ for one year or longer. Three patients, all of whom were attending a renal clinic, survived without renal replacement treatment. for periods of 43,45 , and 46 months respectively
Conclusions-The increased number of new patients disclosed in this survey compared with the earlier survey is mainly owing to an increased number of older patients. Such patients often have disabilities other than renal failure, are less likely to be capable of self treatment, may develop complications more often and require more frequent hospital admissions, and may not be suitable for transplantation and consequently have considerable resource implications for the NHS.

\section{Introduction}

In 1984 members of the Renal Association became concerned about the shortfall of treatment provided for patients reaching end stage renal failure. They were well aware that in the United Kingdom standards were falling far short of those in Europe and the United States for levels of treatment, especially for older patients and for those with concurrent medical problems, such as diabetes mellitus. It had also become clear that there was considerable inequality in the facilities available in different parts of the United Kingdom. The association therefore decided to set up a subcommittee to investigate the number of patients who were likely to benefit from treatment and to assess the level of service provision and any shortfall in facilities.

Data were available on the number of patients receiving treatment through the statistics collected by the European Dialysis and Transplant Association. 